\title{
PARK11 is not linked with Parkinson's disease in European families
}

Jürgen Prestel ${ }^{1,10}$, Manu Sharma ${ }^{1,10}$, Petra Leitner ${ }^{1}$, Alexander Zimprich ${ }^{1}$, Jenny R Vaughan ${ }^{2}$, Alexandra Dürr ${ }^{3}$, Vincenzo Bonifati ${ }^{4,5}$, Giuseppe De Michele ${ }^{6}$, Hasmet A Hanagasi ${ }^{7}$, Matthew Farrer ${ }^{8}$, Anne Hofer ${ }^{1}$, Friedrich Asmus ${ }^{1}$, Giampiero Volpe ${ }^{6}$, Giuseppe Meco $^{4}$, Alexis Brice ${ }^{3}$, Nicholas W Wood ${ }^{2}$, Bertram Müller-Myhsok ${ }^{9}$, Thomas Gasser ${ }^{*}, 1$ and The European Consortium on Genetic Susceptibility in Parkinson's Disease (GSPD)

\footnotetext{
${ }^{1}$ Hertie-Institute for Clinical Brain Research, Department of Neurodegenerative Diseases, University of Tuebingen, Germany; ${ }^{2}$ Department of Molecular Neuroscience, Institute of Neurology, Queen Square, London, UK; ${ }^{3}$ INSERM U289 and Department of Genetics, Cytogenetics and Embryology, AP-HP, Salpetriere Hospital, Paris, France; ${ }^{4}$ Department of Neurological Sciences, La Sapienza University, Rome, Italy; ${ }^{5}$ Department of Clinical Genetics, Erasmus MC Rotterdam, The Netherlands; ${ }^{6}$ Department of Neurological Sciences, Federico II University, Naples, Italy; ${ }^{7}$ Department of Neurology, Istanbul Faculty of Medicine, Istanbul University, Istanbul, Turkey; ${ }^{8}$ Departments of Neurology and Neuroscience, Mayo Clinic Jacksonville, Jacksonville, FL 32224, USA; ${ }^{9}$ Max-Planck-Institute of Psychiatry, Munich, Germany
}

Parkinson's disease (PD) is a genetically heterogeneous disease. Recently, significant linkage has been reported to a $39.5 \mathrm{cM}$ region on the long arm of chromosome 2 (2q36-37; PARK11) in North American Parkinson families under an autosomal dominant model of inheritance. We have performed a replication study to confirm linkage to this region in a European population. Linkage analysis in 153 individuals from 45 European families with a strong family history of PD did not show any significant LOD score in this region. Therefore, PARK11 does not seem to play a major role for familial PD in the European population. European Journal of Human Genetics (2005) 13, 193-197. doi:10.1038/sj.ejhg.5201317

Published online 3 November 2004

Keywords: PARK11; 2q36-37; Parkinson's disease; linkage analysis

\section{Introduction}

Parkinson's disease (PD) (MIM 168600) is the second most common neurodegenerative disorder after Alzheimer's disease. It affects $1.8 \%$ of the individuals, who are 65 years of age and older. ${ }^{1}$ It is characterized by bradykinesia, rigidity, resting tremor and postural instability. Pathological hallmarks of PD involve the degeneration of dopaminergic

\footnotetext{
*Correspondence: Professor Dr T Gasser, Hertie-Institute for Clinical Brain Research, Section for Neurodegenerative Diseases, University of Tuebingen, Hoppe-Seyler Str. 3, 72076 Tuebingen, Germany. Tel: + 49707129 86529; Fax: + 49707129 4839;

E-Mail: Thomas.Gasser@med.uni-tuebingen.de

${ }^{10}$ These two authors contributed equally to the work.

Received 5 July 2004; revised 9 September 2004; accepted 10 September 2004
}

neurons in the substantia nigra pars compacta and the formation of Lewy bodies. ${ }^{2,3}$

While the cause of PD is unknown, there is increasing evidence for a significant genetic component in idiopathic PD. Epidemiological studies showed that the risk of PD is at least doubled in first-degree relatives as compared with controls. ${ }^{4}$ To date, six genes and several loci for monogenically inherited forms of PD - which account only for a small fraction of the diseases - have been identified or localized: mutations in the parkin gene ${ }^{5}$ (PARK2 (MIM 602544)), in the PINK1 gene ${ }^{6}$ (PARK6 (MIM 605909)) and in the DJ-1 gene $^{7}$ (PARK7 (MIM 602533)) cause autosomal recessive early-onset parkinsonism, while missense mutations in the $\alpha$-synuclein gene ${ }^{8}$ (PARK1 [MIM 168601]) and recently duplications and triplications of the wild-type $\alpha$ synuclein locus ${ }^{9,10}$ were found in a small number of families 
Table 1 Characteristics of the families

\begin{tabular}{|c|c|c|c|c|c|c|}
\hline \multirow[b]{2}{*}{ Country } & \multirow[b]{2}{*}{ Number of families } & \multicolumn{2}{|c|}{ Number of sibs } & \multirow[b]{2}{*}{$\%$ Male } & \multirow[b]{2}{*}{$\%$ Female } & \multirow{2}{*}{$\begin{array}{c}\text { Mean } \pm S D \\
\text { Age at onset (years) }\end{array}$} \\
\hline & & Affected all/genotyped & Unaffected all/genotyped & & & \\
\hline German & 19 & $48 / 39$ & $37 / 18$ & 49.6 & 50.4 & $59.4 \pm 8.3$ \\
\hline English & 11 & $35 / 24$ & $44 / 24$ & 46.3 & 53.7 & $58.3 \pm 7.3$ \\
\hline French & 7 & $21 / 17$ & $10 / 3$ & 47.1 & 52.9 & $56.4 \pm 12.8$ \\
\hline Italian & 6 & $18 / 14$ & $14 / 8$ & 47.8 & 52.2 & $52.8 \pm 16.6$ \\
\hline \multirow[t]{2}{*}{ Turkey } & 2 & $8 / 6$ & $18 / 0$ & 52.0 & 48.0 & $61.0 \pm 4.2$ \\
\hline & 45 & $130 / 100$ & $123 / 53$ & 48.2 & 51.8 & $57.6 \pm 10.5$ \\
\hline
\end{tabular}

with autosomal dominant PD. The UCH-L1 mutation (PARK5 (MIM 191342)) has been reported in a single German family. ${ }^{11}$ Recently, mutations in the NR4A2 or NURR1 gene (MIM 601828) were found in families with late-onset PD. ${ }^{12}$ In addition, genetic studies have detected linkage to several chromosomal regions which might contain susceptibility loci for PD: PARK3 (MIM 602404), ${ }^{13}$ PARK8 (MIM 607060), ${ }^{14}$ PARK9 (MIM 606693) ${ }^{15}$ and PARK10 (MIM 606852). ${ }^{16}$

Evidence for linkage to chromosome 2q36-37 (PARK11 (MIM 607688)) was first detected in a sample of 160 families (170 affected sibling pairs) in a genome-wide screen. ${ }^{17}$ An additional study was performed using a subset of the previous, but expanded sample, which included only pedigrees with a strong family history of PD: in an analysis of 65 families (77 sibling pairs) a maximum LOD score of 5.1 at the marker D2S206 on chromosome 2q36-37 was found using an autosomal dominant model of disease transmission. ${ }^{18}$ Recently, Pankratz et al ${ }^{19}$ confirmed their previous results using a further enlarged sample of 85 families (113 sibling pairs) with a strong family history of PD: they again reported a linkage to the 2q36-37 region (LOD score 4.9).

\section{Materials and methods}

We have performed a replication study in a set of European sib pair families to verify the linkage at 2q36-37 in a European population. In all, 45 families were selected for this study. We included families with a strong family history of PD, defined according to the same criteria regarding family history as used by Pankratz et al: the families had at least four first-, second- or third-degree relatives reported to have $\mathrm{PD}$, or they included an affected sibling pair who also had a parent reportedly diagnosed with PD. Of our 45 families, 15 included at least one affected individual with an age of onset $\leqslant 50$ years. The diagnosis of $\mathrm{PD}$ in the index patients was established according to the UK Parkinson's Disease Society Brain Bank criteria. ${ }^{20}$ After appropriate informed consent was obtained, blood samples had been drawn from the individuals for DNA extraction. The characteristics of the families are described in Table 1.

Pankratz et al reported a significantly linked region between marker D2S126 and D2S125 spanning a distance of $39.5 \mathrm{cM}$. We have selected only that region for analysis where the highest LOD score was reported. Six markers (D2S2382, D2S126, D2S396, D2S206, D2S338, D2S125) with an average spacing density of $9.4 \mathrm{cM}$ were used for analysis. These six dinucleotide repeat markers with an average heterozygosity of $82 \%$ were genotyped on chromosome 2. Marker order and genetic distances between the markers were obtained from the sex-averaged genetic map from Marshfield Genetic Laboratories. PCR amplification was performed for each marker in a $10-\mu$ l reaction using $20 \mathrm{ng}$ of genomic DNA, $2 \mathrm{pM}$ of each primer, $0.2 \mathrm{mM}$ of each dNTP, $1 \mu \mathrm{l} 10 \times$ PCR buffer (containing $15 \mathrm{mM} \mathrm{MgCl}_{2}$ ), 0.5 or $1 \mathrm{mM} \mathrm{MgCl}_{2}$ and $0.3 \mathrm{U}$ of Taq DNA polymerase (Taq PCR Core Kit, Qiagen). Amplification conditions were as follows: preincubation at $94^{\circ} \mathrm{C}$ for $2 \mathrm{~min}, 35$ cycles of denaturation at $94^{\circ} \mathrm{C}$ for $30 \mathrm{~s}$, annealing at $56^{\circ} \mathrm{C}$ or $60^{\circ} \mathrm{C}$ for $30 \mathrm{~s}$ and extension at $72^{\circ} \mathrm{C}$ for $40 \mathrm{~s}$ and final extension for $2 \mathrm{~min}$ at $72^{\circ} \mathrm{C}$. In all, $1 \mu \mathrm{l}$ of the PCR product was added to $20 \mu \mathrm{l}$ of formamide containing the GeneScan-500 ROX size standard. The products were separated by capillary electrophoresis using an ABI PRISM 3100-Avant Genetic Analyzer (Applied Biosystems). The genotypes were determined by using GeneScan version 3.7. Mendelian inconsistencies in the genotypic data were checked by using the program PedCheck. $^{21}$

In order to evaluate the power of our sample, a simulation study was performed by using the SLINK program. ${ }^{22}$ It showed that our sample size is sufficient for finding significant evidence for linkage, with an average maximum LOD score of $Z=2.8$. Two-point LOD scores were calculated using the MLINK programme of LINKAGE software package. ${ }^{23}$ The mode of inheritance was set as autosomal dominant with a disease allele frequency of 0.005. Marker allele frequencies were based on all individuals genotyped. The penetrance was set at $40 \%$ for $\leqslant 50$ years and at $80 \%$ for $>50$ years of age. The phenocopy rate 
Table 2 Results of the parametric and nonparametric analysis: multipoint LOD scores

\begin{tabular}{|c|c|c|c|c|c|}
\hline \multirow[b]{2}{*}{ Marker } & \multirow[b]{2}{*}{ Distance $(c M)^{c}$} & \multicolumn{2}{|c|}{ LOD score 45 families } & \multicolumn{2}{|c|}{ LOD score 36 families } \\
\hline & & $M L O D^{a}$ & $N P L^{\mathrm{b}}$ & $M L O D^{\mathrm{a}}$ & $N P L^{\mathrm{b}}$ \\
\hline $\begin{array}{l}\text { D2S2382 } \\
\text { D2S126 } \\
\text { D2S396 } \\
\text { D2S206 } \\
\text { D2S338 } \\
\text { D2S125 }\end{array}$ & $\begin{array}{c}0 \\
7.6 \\
19.4 \\
27.29 \\
37.04 \\
47.13\end{array}$ & $\begin{array}{l}-5.78 \\
-3.01 \\
-5.48 \\
-7.01 \\
-3.38 \\
-6.13\end{array}$ & $\begin{array}{l}0.45 \\
0.6 \\
0.24 \\
0.13 \\
0.15 \\
0.07\end{array}$ & $\begin{array}{l}-5.8 \\
-3.61 \\
-3.39 \\
-5.01 \\
-2.74 \\
-4.71\end{array}$ & $\begin{array}{l}0.28 \\
0.48 \\
0.27 \\
0.18 \\
0.18 \\
0.08\end{array}$ \\
\hline
\end{tabular}

${ }^{\mathrm{a}} \mathrm{MLOD}=$ multipoint maximum parametric lod score.

${ }^{\mathrm{b}} \mathrm{NPL}=$ multipoint nonparametric linkage score, $S_{\text {all. }}$.

${ }^{\mathrm{C}}$ Distances in Haldane cM.

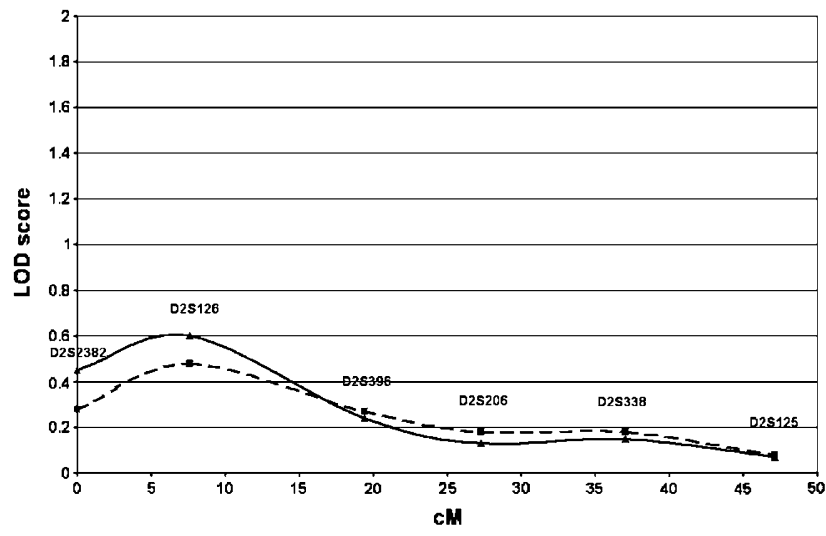

Figure 1 Results of the multipoint nonparametric linkage analysis. Multipoint LOD score graph for 45 families (solid line) and 36 families (dashed line).

was assumed as $2 \%$. Multipoint parametric and nonparametric analysis was carried out by using SimWalk 2 version 2.89. ${ }^{24}$ The sib transmission/disequilibrium test (S-TDT) was used to observe the transmission of alleles among affected sibs. $^{25}$

In the 15 families, that included at least one affected individual with an age of onset $\leqslant 50$ years, a marker in intron 7 of the parkin gene (D6S305) was genotyped in order to identify families more likely to have a mutation in this known PD-susceptibility gene. Linkage analysis was repeated excluding those families showing possible linkage to D6S305.

\section{Results}

We did not obtain any significant LOD score in the parametric analysis, nor in the nonparametric analysis: the results are shown in Table 2, Figure 1 and in the online information (see supplementary information: Tables 3 and 4). The highest LOD score (0.6) was found in the multipoint nonparametric analysis at marker D2S126 (Table 2, Figure 1).

We did not observe any significant $z$ score in the S-TDT, which showed that none of the marker alleles is associated with the disease. The results of the S-TDT are shown in the supplementary information (Table 5). In our families, we could not perform the TDT test, because parental genotypes were not available. There is probably not much loss of power, when the parents are not genotyped as in our case, given the fact that affected sibs as well as unaffected sibs are genotyped.

Linkage to marker D6S305 in the parkin gene could not be excluded in nine of the 15 families, that included at least one affected individual with an age of onset $\leqslant 50$ years. Excluding these nine families, we did not obtain any significant LOD score in the parametric nor nonparametric linkage analysis of the remaining 36 families. Again, the highest LOD score $(0.48)$ was found in the nonparametric analysis at marker D2S126.

\section{Discussion}

The studies by Pankratz et al showed a significant linkage of PD to 2q36-37 in a North American population. The sample of Pankratz et $a l^{17,19}$ was primarily Caucasian (94\%), although Hispanics (5\%) also participated. Interestingly, the Hispanic families in the sample provided a substantial portion of the linkage evidence. ${ }^{19}$ We could not find a significant linkage to this region in our European families.

The discrepancy of the results between both studies might be explained by the different population. However, none of the other PD genome-wide linkage studies in the last years have reported evidence of linkage to chromosome 2q: DeStefano et $a^{26}$ included affected sibling pairs mainly from the United States and also from Canada, Germany and Italy, Scott et $a l^{27}$ analysed white families from the United States and Australia, while Hicks et al ${ }^{16}$ performed a scan on Icelandic families. 
Pankratz et al reported a significant LOD score both in a sample with and without parkin mutations. The inclusion of the families with parkin mutations resulted in a higher LOD score, but the LOD score remained clearly significant in the sample without parkin mutations. ${ }^{18,19}$ We repeated our linkage analysis excluding nine families, in which we could not rule out linkage to marker D6S305 in the parkin gene. Excluding these families did not change our overall results, indicating that there is no specific contribution of this subset of families to our results. It is also unlikely that the parkinsonism in these nine families is caused by parkin mutations, because we included only families compatible with autosomal dominant inheritance in our study and mutations in the parkin gene cause autosomal recessive parkinsonism (with the exception of very few families, in whom the contribution of the parkin mutation is still somewhat controversial).

A possible linkage of our families to other dominant PD loci such as PARK3 and PARK8 was not subject of this study and cannot be excluded.

The mean age of onset in our PD families $(57.6 \pm 10.5$ years) was similar to the mean age at onset in the studies of Pankratz et al: $58.0 \pm 12.2$ years, ${ }^{18} 58.3 \pm 12.0$ years. ${ }^{19}$ This indicates that the discrepancy of the results between the studies by Pankratz et al and our study cannot be explained by a different age at onset of PD in the population.

We genotyped the same six markers as Pankratz et al in the region, where the highest LOD score was reported. Thus, the discrepancy of the results between the studies cannot be explained by a different marker density. Employing a denser set of markers would most probably not affect our overall results.

It may be argued that the original study by Pankratz et al overestimated the linkage, so that the true effect conferred by the PARK11 locus is smaller, and therefore escaped detection in our sample. We did not find a significant LOD score in our analysis. The highest LOD score of our study occurred in the nonparametric analysis at marker D2S126 (LOD score 0.6) and is far away from significance. The marker D2S126 is nearly $20 \mathrm{cM}$ apart from D2S206, where the highest LOD score was reported by Pankratz et al.

In summary, our study did not provide evidence of a susceptibility locus for Parkinson's disease at 2q36-37 in our families. Therefore, PARK11 does not seem to play a major role for familial PD in the European population. A susceptibility locus at 2q36-37 may be a rare form, occurring in specific populations.

\section{Acknowledgements}

The study was supported by the German Ministry for Education and Research (BMBF - Parkinson Competence Network (01GE0201) and German National Genome Research Network NGFN (01GS01116)), Udall Center of Excellence in Parkinson disease (P01 NS40256) and the Hertie Institute for Clinical Brain Research, Tuebingen, Germany.

\section{Electronic-database information}

The URLs for data presented herein are as follows

Center for Medical Genetics, Marshfield Medical Research Foundation, http://research.marshfieldclinic.org/genetics/ (for the chromosome $2 q$ genetic map).

Online Mendelian Inheritance in Man (OMIM), http://www. ncbi.nlm.nih.gov/Omim/ (for PD, PARK1, PARK2, PARK3, PARK5, PARK6, PARK7, PARK8, PARK9, PARK10, PARK11, NR4A2).

\section{References}

1 de Rijk MC, Launer LJ, Berger K et al: Prevalence of Parkinson's disease in Europe: a collaborative study of population-based cohorts. Neurology 2000; 54: S21-S23.

2 Gibb WR, Lees AJ: The significance of the Lewy body in the diagnosis of idiopathic Parkinson's disease. Neuropathol Appl Neurobiol 1989; 15: 27-44.

3 Fearnley JM, Lees AJ: Ageing and Parkinson's disease: substantia nigra regional selectivity. Brain 1991; 114 (Part 5): 2283-2301.

4 Payami H, Larsen K, Bernard S, Nutt J: Increased risk of Parkinson's disease in parents and siblings of patients. Ann Neurol 1994; 36: 659-661.

5 Kitada T, Asakawa S, Hattori N et al: Mutations in the parkin gene cause autosomal recessive juvenile parkinsonism. Nature 1998; 392: $605-608$.

6 Valente EM, Abou-Sleiman PM, Caputo V et al: Hereditary earlyonset Parkinson's disease caused by mutations in PINK1. Science 2004; 304: 1158-1160.

7 Bonifati V, Rizzu P, van Baren MJ et al: Mutations in the DJ-1 gene associated with autosomal recessive early-onset parkinsonism. Science 2003; 299: 256-259.

8 Polymeropoulos $\mathrm{MH}$, Lavedan C, Leroy E et al: Mutation in the alpha-synuclein gene identified in families with Parkinson's disease. Science 1997; 276: 2045-2047.

9 Ibáñez P, Bonnet AM, Débarges B et al: Causal relation between alpha-synuclein gene duplication and familial Parkinson's disease. Lancet 2004; 364: 1169-1171.

10 Singleton $\mathrm{AB}$, Farrer M, Johnson J et al: Alpha-synuclein locus triplication causes Parkinson's disease. Science 2003; 302: 841.

11 Leroy E, Boyer R, Auburger G et al: The ubiquitin pathway in Parkinson's disease. Nature 1998; 395: 451-452.

12 Le WD, Xu P, Jankovic J et al: Mutations in NR4A2 associated with familial Parkinson disease. Nature Genet 2003; 33: 85-89.

13 Gasser T, Muller-Myhsok B, Wszolek ZK et al: A susceptibility locus for Parkinson's disease maps to chromosome 2p13. Nat Genet 1998; 18: 262-265.

14 Funayama M, Hasegawa K, Kowa H, Saito M, Tsuji S, Obata F: A new locus for Parkinson's disease (PARK8) maps to chromosome 12p11.2-q13.1. Ann Neurol 2002; 51: 296-301.

15 Hampshire DJ, Roberts E, Crow Y et al: Kufor-Rakeb syndrome, pallido-pyramidal degeneration with supranuclear upgaze paresis and dementia, maps to 1p36. J Med Genet 2001; 38: 680-682.

16 Hicks AA, Petursson H, Jonsson T et al: A susceptibility gene for lateonset idiopathic Parkinson's disease. Ann Neurol 2002; 52: 549-555.

17 Pankratz N, Nichols WC, Uniacke SK et al: Genome screen to identify susceptibility genes for Parkinson disease in a sample without parkin mutations. Am J Hum Genet 2002; 71: 124-135.

18 Pankratz N, Nichols WC, Uniacke SK et al: Significant linkage of Parkinson disease to chromosome 2q36-37. Am J Hum Genet 2003b; 72: 1053-1057.

19 Pankratz N, Nichols WC, Uniacke SK et al: Genome-wide linkage analysis and evidence of gene-by-gene interactions in a sample of 362 multiplex Parkinson disease families. Hum Mol Genet 2003a; 12: 2599-2608.

20 Hughes AJ, Daniel SE, Kilford L, Lees AJ: Accuracy of clinical diagnosis of idiopathic Parkinson's disease: a clinico-pathological study of 100 cases. J Neurol Neurosurg Psychiatry 1992; 55: 181-184. 
21 O'Connell JR, Weeks DE: PedCheck: a program for identification of genotype incompatibilities in linkage analysis. Am J Hum Genet 1998; 63: 259-266.

22 Ott J: Computer-simulation methods in human linkage analysis. Proc Natl Acad Sci USA 1989; 86: 4175 -4178.

23 Lathrop GM, Lalouel JM: Easy calculations of lod scores and genetic risks on small computers. Am J Hum Genet 1984; 36: 460-465.

24 Sobel E, Lange K: Descent graphs in pedigree analysis: applications to haplotyping, location scores, and marker-sharing statistics. Am J Hum Genet 1996; 58: 1323-1337.
25 Spielman RS, Ewens WJ: A sibship test for linkage in the presence of association: the sib transmission/disequilibrium test. Am J Hum Genet 1998; 62: 450-458.

26 DeStefano AL, Golbe LI, Mark MH et al: Genome-wide scan for Parkinson's disease: the GenePD study. Neurology 2001; 57: $1124-1126$.

27 Scott WK, Nance MA, Watts RL et al: Complete genomic screen in Parkinson disease: evidence for multiple genes. JAMA 2001; 286: $2239-2244$

Supplementary Information accompanies the paper on European Journal of Human Genetics website (http://www.nature.com.ejhg) 